\title{
Labyrinthe
}

9 | 2001

Numéro 9

\section{Labyrinthe, instigateur du premier Salon de la Revue étudiante}

Samedi 3 mars. Paris, Grande Halle de la Villette.

\section{François-Xavier Priollaud}

\section{(2) OpenEdition}

\section{Journals}

Édition électronique

URL : http://journals.openedition.org/labyrinthe/1129

DOI : $10.4000 /$ labyrinthe. 1129

ISSN : 1950-6031

Éditeur

Hermann

Édition imprimée

Date de publication : 30 juin 2001

Pagination : 124

\section{Référence électronique}

François-Xavier Priollaud, "Labyrinthe, instigateur du premier Salon de la Revue étudiante », Labyrinthe [En ligne], 9 | 2001, mis en ligne le 11 février 2006, consulté le 01 mai 2019. URL : http:// journals.openedition.org/labyrinthe/1129; DOI : 10.4000/labyrinthe.1129

Ce document a été généré automatiquement le 1 mai 2019.

Propriété intellectuelle 


\title{
Labyrinthe, instigateur du premier Salon de la Revue étudiante
}

Samedi 3 mars. Paris, Grande Halle de la Villette.

\author{
François-Xavier Priollaud
}

1 De la France entière, elles étaient une vingtaine à répondre présentes à ce premier Salon de la Revue étudiante, lancé à l'initiative de Labyrinthe, dans le cadre du Forum Anima'Fac des associations étudiantes. De jeunes revues qui jouent dans la cour des grands, il fallait bien la Grande Halle de la Villette pour les accueillir ! Littérature, musique, philo, architecture, histoire, géopolitique, théâtre... des idées et un vivier de talents enfin réunis. «Les revues étudiantes sont-elles différentes ?» C'était le thème du débat public organisé à l'occasion du marché des associations. Différentes, elles le sont tant par leur contenu que par leur mode de fonctionnement, souvent fragilisé par la précarité du statut étudiant. Pour pallier ces faiblesses et favoriser le réflexe d'entraide, un groupe de travail s'est spontanément mis en place et devrait rapidement mener à bien des projets communs prometteurs. Cette volonté d'union associée à des échanges fructueux nous a permis de poser le premier maillon d'un véritable réseau de jeunes revues : réseau d'auteurs, réseau de financement et réseau de diffusion. La construction prochaine d'un site internet nous aidera à remplir ces objectifs. C'est un pari ambitieux, un pari stimulant pour la diffusion de la « littérature grise »! À nous d'imaginer et de construire, tous ensemble, la fédération des jeunes revues, une fédération ouverte, plurielle et solidaire. 